\title{
Library Group Practice
}

A plan for library group practice bears several striking similarities to a medical group practice, both in rationale and in patterns of service. Library group practice is a means of enhancing professional achievement, improving the rate of productivity in libraries, and thereby offering one way in which information can be marketed by libraries at an acceptable price.

\begin{abstract}
A
A cademic libraries are changing. They must change. Library costs have risen while the rate of productivity has remained virtually the same, with the result that the information product has nearly been priced out of the market. ${ }^{1}$ Librarians must devise new ways of producing their product so that it will be within the reach of users.
\end{abstract}

Academic librarians are also faced with the issue of professionalism which has been forced by ACRL's adoption of the "Standards for Faculty Status for College and University Librarians." Faculty status, to be meaningful, must include the respect of the faculty and students. Professionalism and respect do not come automatically from the bestowal of faculty status or a decree from ACRL, but from a recognition of quality and, equally, the level of work accomplished.

True academic status requires greater professional performance and behavior on the part of librarians than patrons have generally been led to expect. Eldred Smith speaks directly to this point when he says of academic libraries:

If anything, they have too many librarians now: most of them spend

Mr. Auld is head, Technical Services, and $M s$. Voit is reserve book room librarian at Oregon State University library, Corvallis. the bulk of their time doing clerical work which nonprofessional personnel can perform equally well for substantially less money. What academic libraries do need is fewer but better-educated librarians who can step into the collection-development, substantial-reference, and bibliographical-consultant positions that are now largely unfilled. ${ }^{3}$

In other words, genuinely professional performance or the utilization of improved educational levels is a rarity. A different pattern, designed to recognize and make use of specialties rather than generalities, is required. ${ }^{4}$

It is the purpose of this paper to propose a plan whereby reference librarians can perform in a more professional manner and at the same time raise their level of productivity.

\section{Service Functions}

The public service or reference function is to act as an interface among the three corners of a triangle-the collection, the catalog and indexes through which the collection is made accessible, and the user. To make this interface effective requires three levels of activity: locational advice, instruction and guidance, and in-depth assistance and consultation. 
Each level requires more and more specific knowledge, with the third level often requiring the skills of an information specialist. It is at this level that the user is in need of a co-worker to aid in locating information; a specialist to assist with a particular problem; or a consultant to confer with on how best to organize a search strategy, select appropriate informational tools and sources, or interpret, evaluate, and apply information.

In theory, in the legal profession it is assumed that, once a lawyer has qualified to practice law within a state, he is competent to handle all types of cases ranging from drawing up wills to civil suits and criminal cases. In reality, a quick survey of legal figures, past and present, makes it evident that specialization does take place.

Libraries follow a similar fiction in saying that the professional is presumed to be equally capable of undertaking work in acquisitions, cataloging, reference, circulation, or administration; or in humanities, social sciences, or science and technology. But, can the English major become the instant subject specialist serving engineers or economists?

The medical profession has approached this matter rather differently and, it would seem, more effectively as well as more honestly. In a field where specialization has become the rule rather than the exception for a majority of physicians and their supportive staffs, there has been an attempt to free the doctor of as many of the routine details, procedures, and technical matters as possible. This leaves him with only those duties which require his professional knowledge, training, and judgment. In order that his skills can be used most effectively, he will often further specialize and become concerned with only certain aspects of the patient's health. Increasingly, the general practitioner acts as a referral agent for the more specialized members of the medical profession. A universal grounding in general practice provides a common language to make possible communications, referral, and consultation.

"The need to make specialized practice workable and adaptable to total patient care" is one reason suggested for the growth of group practice in the medical profession. ${ }^{5}$ In other words, physicians practiced as individuals until specialization made it desirable to work together. Librarians, on the other hand, work together even when specialization is so slight as not to be an influence. One explanation might be that the method of compensation and the ownership of tools (books) dictates where and with whom librarians work. But, whereas physicians come together in order to better utilize their specializations, librarians are already together and have done little in the way of studying how best to utilize their collective capabilities.

There are distinct similarities between a medical group practice and a library. The chief ones are: the client (patient/ user) comes in need; rapid increases in accumulated knowledge have led to specialization or the need for specialization; specific practices, procedures, and services can be categorized according to the level of professional judgment required; continuing growth of knowledge and technological development point to an even more complex future requiring even more specialization; and finally, the client expects that future services will exceed past services, especially in quality.

The essential points of dissimilarity remain, but they really boil down to the treatment of disease $v s$. the servicing of information. This difference in content in no way invalidates the marked similarities in service patterns noted above. That being the case, we should consider which service features of the prosperous and successful field of medical 
group practice can be adopted by librarians whose prosperity and success are rather less notable.

The medical group practice model evolved from a systematic sorting of medical and supportive activities according to the form and type of training required-by the level of professional judgment required to perform each activity. Each level of activity is staffed by persons specifically hired and trained to perform that level of activity. Thus, the medical group (and its supporting staff) may include such varied positions as neurologist, pediatrician, laboratory technician, pharmacist, registered nurse, receptionist, bookkeeper, and janitor. The guiding rule is that no one presumes to offer judgments above or beyond those he is professionally trained and qualified to make. Thus, a nurse may recognize the symptoms of a disease, but only a physician gives voice to a diagnosis or prescribes treatment. This is a crucial factor in the success of the medical group practice structure in its day-to-day functioning for without a careful and systematic regard for this distinction among the many levels of professional judgment the group practice structure would fail in its objectives.

\section{Library Group Practice Concept}

Library group practice would also require that activities be sorted systematically according to the form and type of training required-by the level of professional judgment required to perform each activity.

The group of activities surrounding locational advice is largely amenable to performance by nonprofessional personnel since scant (if any) professional judgment is required to direct the user to the water cooler, the card catalog, the dictionary stand, or the director's office.

The group of activities surrounding instruction requires more professional judgment than locational advice, but not enough to require exclusively professional personnel. Much of the routine instruction in the use of the card catalog, indexes, and other basic tools is highly repetitious and can be competently handled by a trained library assistant or technician. (Indeed, this can often be recorded and made available on-demand to meet the user's specific needs.)

More detailed guidance requires somewhat greater professional judgment in the form of a professional person but one with only a general and basic grasp of library science, i.e., the librarian lacking experience or a particular specialization. There can be a close parallel between the librarian performing this guidance function and the general practitioner providing only basic and referral medical services, for it is at this level that a determination must be made as to whether or not the patron is in need of research assistance or consultation which require professional judgment and often a high degree of specialization as well. The most efficient way of supplying this highest level of service is to have well-trained and specialized professionals who are on call or available by appointment to deal with specific user needs.

When a patient enters a medical group practice facility, he expects to be met by a receptionist who will direct him to particular persons and offices and who will make appointments for him. The professional is removed to a location where he can be more effective in working with individual patients without unnecessary distractions, noise, and confusion.

Similarly the library user, on entering a group practice library, should expect to be met by an information clerk who will determine what levels of service are required, direct the patron to the person who can be of assistance, and set up an appointment with the appropriate consultant-specialist. Again, the profession- 
al is removed from unnecessary distractions so that he can function more effectively and is free to exercise his other professional responsibilities which may include going outside the library as a floating librarian. ${ }^{6}$

For librarians to set up a group practice, it will be necessary to reorder priorities and assumptions. A librarian will be required to function at the level for which he is trained and only at that level. No longer can we insist that "every user have contact with a professional librarian." No longer can professionals absorb (willingly, eagerly, or otherwise) huge quantities of clerical routine "because it has to be done." No longer can the highly qualified and thoroughly experienced specialist devote a substantial share of his time to "sitting at the reference desk." Group practice requires that instead of everyone sharing and sharing-alike, each assume the responsibility for that level of work for which he is professionally qualified.

The ideal composition of the library staff and its organization would be clerical-professional ratios of at least twoor three-to-one (as recommended by the Canadian Association of College and University Libraries). ${ }^{7}$ The ALA statement on Library Education and Manpower describes a logical and sound progression from clerical assistant to senior librarian and, in a supplementary statement, equivalents are also delineated so that individuals lacking training in library science but possessing an equal level of training in another discipline can be placed within the library structure at a suitable level where they can work and be compensated appropriately. ${ }^{8}$ The essential corollary is that each staff member understand that he must not overstep his training and competence: he must not presume to offer service beyond the level for which he is qualified.

Formation of a group practice must have the enthusiasm and support of the professional staff if it is to be effective; the librarians in turn must promote the group practice idea. At first, it will be necessary to secure the sympathy, cooperation, and understanding of academic administrators, boards of trustees, civil service commissions, and employee associations and organizations who must be convinced of the advantages of group practice. The mutual advantages to be gained from each person doing those tasks for which he is trained and qualified should become self-evident to them.

Group practice will permit optimum use of each staff member's training, ability, and experience. As the more expensive professional is relieved of tasks which can be performed satisfactorily by other persons, the return per dollar invested will be improved. Also, such reassignment will tend to enlarge the total reservoir of professional staff. The quality of service will have been improved, which should attract additional users. If not, it may be necessary to trim surplus staff. Either way, the per-unit cost of service will be held down. Clearly then, the group practice concept can contribute directly to an increase in the rate of productivity of librarians and enhance the quality of service at the same time.

\section{SUMMARY}

The concept of library group practice, the systematic working together of specialist librarians and supportive staff in a format modeled after medical group practice, has been briefly explored. The purpose of forming a library group practice is to enhance the service capabilities of the library by making optimum use of all levels of staff and thereby improving the costbenefit ratio and increasing the librarian's rate of productivity.

Technological and postindustrial society cannot exist without information; in fact, much of the commerce in such 
a society will be in information itself. braries are also to continue to exist, they There is no question: information as must turn out a marketable product a utility will continue to exist. If li- which the user can afford.

\section{REFERENCES}

1. Frederick G. Kilgour, "The Economic Goal of Library Automation," CRL 30:307-11 (July 1969).

2. CRL News June 1971 and Sept. 1972.

3. Eldred Smith, "Academic Status for College and University Librarians-Problems and Prospects," CRL 31:11 (Jan. 1970).

4. John H. Moriarty, "Academic in Deed," CRL 31:17 (Jan. 1970); Herbert S. White, "Professional Identity: Revolt of the Scientists," Wilson Library Bulletin 44:554 (Jan. 1970).

5. Group Practice: Guidelines to Forming or Joining a Medical Group produced as a combined effort of [the] American Association of Medical Clinics, [the] American Medical Association [and the] Medical Group Management Association (1965).

6. Robert P. Haro, "The Floating Academic Librarian," American Libraries 2:1169-73 (Dec. 1971).

7. Canadian Association of College and University Libraries. University Library Standards Committee: Guide to Canadian University Library Standards ([Ottawa?] 1965), p. 5 .

8. "Library Education and Manpower," American Libraries 1:341-44 (April 1970); "Supplementary Note," American Libraries 1:665 (July/Aug. 1970). 